\section{Impfschutz von Migrantenkindern verbessern}

\section{In Regionen mit hohem Migrantenanteil können Vertrauenspersonen als „Brücke" zwischen Gesundheitsamt und Eltern mit Erfolg eingesetzt werden.}

D as „Altländer Viertel“ von Stade zeichnet sich durch einen hohen Prozentsatz ausländischer Staatsbürger (49\%) aus. 76 von 100 Kindern und Jugendlichen beziehen Hilfe zum Lebensunterhalt.

Eine erste Intervention der Behörden, in der die Eltern der Kinder über die Mumps-Masern-Röteln-(MMR)-Impfung informiert wurden, brachte nur wenig Erfolg: Nur 60\% der Kinder verfügte bei den Schuleingangsuntersuchungen in den Jahren 2000 bis 2002 über einen Imfpass - $25 \%$ weniger als im Landkreisdurch- schnitt. Nur 7\% waren zweimal mit der MMR-Vakzine geimpft worden.

Der Gesundheitsdienst änderte daraufhin seine Taktik und setzte auf Vertrauenspersonen. Es handelte sich dabei um Migranten, die als ehrenamtliche Vermittler zwischen Behörden und Familien fungierten. Sie konnten mit dem gleichem kulturellen Hintergrund besser Kontakte zu den Eltern knüpfen und sie über die Vorteile der Impfung informieren.

Am Ende der zwölfjährigen Interventionszeit besaßen neun von zehn Kindern aus dem Stadtviertel einen Impfpass. 91\% der Kinder hatten zweimal den MMRImpfstoff erhalten.

Fazit: Auch in Gebieten mit hohem Migrantenanteil lassen sich Eltern vom Sinn einer Impfung für ihre Kinder überzeugen. Informationen durch die Behörden allein reichen dabei nicht aus. Erst das Zwischenschalten von Vertrauenspersonen mit Zugang zur Herkunfts- wie auch zur Aufnahmekultur brachten den gewünschten Erfolg. Dr. Robert Bublak

Bericht des Kinder- und Jugenärztlichen Dienstes des Gesundheitsamtes Stade: Verbesserung des MMR-Impfschutzes bei Migrantenkindern in einem sozialen Brennpunkt in Deutschland. Epidemiologisches Bulletin 34/2012: 343-5

\title{
HIV-Selbsttest in USA zugelassen
}

- Die US-amerikanische Arzneimittelbehörde hat den ersten freiverkäuflichen HIV-Selbsttest zugelassen. Er benötigt keine Blutprobe und liefert in weniger als einer Stunde das Ergebnis.

Als enormen Fortschritt in der Erkennung des HI-Virus feierten die Arzneimittelaufsichtsbehorde FDA und der Gerätehersteller Ora-SureTechnologies den HIV-Selbsttest, der nun die Zulassung in den USA erhalten hat. Das „Ora Quick In-home“ genannte Analysegerät soll im Oktober auf den Markt kommen und voraussichtlich weniger als 20 Euro kosten.

Für den Test wird ein Abstrich der Mundschleimhautbenötigt. Das Ergebnis kann innerhalb von 20 bis 40 Minuten abgelesen werden.
Klinische Studien haben eine Sensitivität von 92\% ergeben. Die FDA machte darauf aufmerksam, dass damit falsch-negative Ergebnisse immerhin bei jedem zwölften Test zu erwarten seien.

Fazit: Die Zulassungsbehörde warnt, der Heimtest könne keine letzte Sicherheit liefern. Ein Arztbesuch bleibe erforderlich - vor allem dann, „wenn der letzte Kontakt (zu HIV-Infizierten) innerhalb der vorangegangenen drei Monate stattfand“. Die Rate der falsch-positiven Testergebnisse soll bei 1:5.000 liegen. Prof. Dr. Kurt Malberg

Pant Pai N et al. Lancet Infect Dis 2012; 12: 373-80 